\title{
STRENGTH OF SEDIMENTS IN THE GULF OF MEXICO
}

\section{Chapter 12}

\section{STRENGTH OF SEDIMENTS IN THE GULF OF MEXICO}

\author{
Parker D. Trask \\ Institute of Engineering Research \\ University of Californis \\ Berkeloy, California
}

\section{INTRODUCT ION}

The strength of the sediments in the Gulf of Mexico concerns the engineer in planning drilling operations. The length and number of piles to support drilling platforms depends upon the strength of the mud. Likewise, the size and type of anchors used in securing service barges is influenced by the strength of the sediments. In the early stages of developing the offshore oil resources in a new area, the engineer is handicapped by lack of information as to the nature of the sediments that must support his structures. As time goes on, he can base his decisions more and more on experience gained in previous construction operations in or near the area with which he is concerned. He gradually acquires a mass of data on pile loading tests, settlement and deformation of existing structures, and laboratory analyses of undisturbed samples. He then can design his structure with confidence. However, in the early stages of the drilling program in any large offshore region, such as the Gulf of Mexico, he is confronted with uncertainties, many of which are difficult to resolve because of lack of definite information upon the strength of the muds.

The geologist can help the engineer greatly in this phase of development of the area, because the strength of the sediments depends upon their geologic characteristics. Basically the strength is determined by the composition and geologic history of the sediments. Four factors are fundamental: (1) size distribution of particles, (2) mineralogical composition, particularly the type of clay minerals, (3) the imposed load, and (4) the length of time the load has been applied. Each of these factors is an essentially independent variable, though under certain circumstances they may be related to one another to a minor extent. For example, the rate of growth of new clay minerals might vary with size of particles, the load, or the length of time. Other factors, of course, influence the strength, but ordinarily to a much less extent than the four variables just mentioned. Among those that might be considered are: (1) desiccation, (2) shape of particlos, (3) comentation, (4) circulating water, (5) base exchange, (6) biological activity, (7) hydrogen-ion concentration, (8) temperature, (9) seasonal variations in temperature, (10) composition of interstitial water, (11) reducing potential, (12) earthqualce vibrations, (13) diastrophic defornation, (14) tidal range, (15) barometric variations, and (16) erosional history. Several of these factors are not completely independent in their effect, as they are related to the four principle variables, and also to one another. As a rule they exert only a minor effect on strength; but at tines some of them, as is discussed below, may affect 


\section{COASTAL ENGINEERING}

the strength significantly. However, in the present analysis of the problem, the four principal factors listed above have by far the greatest engineering significance.

The relationship between strength and the four primary variables has not yet been worked out, but progress has been made. The rapid development of soil mechanics, under the leadership of Terzaghi and Casagrande, has helped very materially in understanding the relationship between strength and the properties of sediments. Trask and Rolston (1950, 1951) have been endeavoring to approach the problem geologically. Since the geologic nature and history of sediments vary from region to region, empirical relations between strength and nature of sediment in any one area cannot necessarily be applied to another area. In any event, in order to obtain effective interpretation of strength from geologic information, specific engineering date on strength must be correlated with geologic data, but where relationships between strength and nature of sediment have been developed for one region, those data can be applied throughout that area according to the principles of geologic correlation; because sediment of similar geologic origin and similar geologic history will have much the same engineering characteristics throughout the region under consideration. The problem of the goologist is to determine the variations of the properties of the sediment from place to place and to ascertain how they affect the strength.

\section{MAJOR FACTORS INFLUENCING STRENGTH}

The most fundamental property influencing the strength is the grain size distribution. A sediment is composed of a mixture of particles of different sizes. The average size of particles differs from one sediment to another. If the particles are coarse, the sediment is a sand, if they are fine, it is a silt or a clay. The average grain diameter is the most useful single figure in describing a sediment. This diameter is colled the median, $\mathrm{D}_{50}$, and represents the diameter that divides the sediment into two equal halves by weight with respect to size. One-half the weight of the particles is composed of perticles larger than the median, and one-half is composed of particles smaller than the median. Ar mentioned below, most of the fundamental characteristics of sediments, such as water content, grain size, and shear strength are directly related to the average grain size. For further details of grain size characteristics, soe Krumbein \& Fttijohn (1938, pp. 228-267).

The strength properties, however, vary with the distribution of particle size on either side of the median. For example, if all the particles are of nearly the same size as the median; that is, if the semple is well sorted according to the geologist, or poorly graded according to the engineer, it is likely to be weaker, because the grains to not interlock as effectively as when they vary widely with respect to size and are well graded. Similarly the particles may be more concentrated with respect to size on one side of the median than on the other. That is, the size distribution may be skewed. The extent of skewriess affects the strength properties significantly. For examplo, 


\section{STRENGTH OF SEDIMENTS IN THE GULF OF MEXICO}

if a sediment composed mainly of clay particles also contains considerable sand, it ordinarily is appreciably stronger than if it contains no sand. On the other hand, if a moist sediment composed largely of sand also contains considerable clay, it is likely to be weaker than if it consists entirely of sand. Ordinarily, sediments are described in terms of the three parameters - median, sorting, and skewness, but in this paper attention is focussed on the median, as it is the dominant factor affecting strength.

The water content, $W / S$, the ratio of the weight of the water (W) to the weight of the solid constituent (S), is generally recognized to be an index of the strongth of the sediments (Terzaghi and Peck, p. 27). The greater the water content, the weaker is the sediment. The water content is not an absolute measure of strength, because all sediments of the same water content do not have the same strength. At least three factors influence this relationship: (1) the type of clay mineral, (2), variations in size distribution with respect to the median, and (3) desiccation, or drying, of the sediment.

Basically the water content varies with the average grain size. Fine sediments contain much water, coarse sediments, little water. The forces between the water molecules and the surface of the mineral grains they wet seem to be the principle factors involved. The total surface area of the particles in a fine sediment is greater than in a coarse sediment. Every particle is surrounded by layers of water molecules, each with its own forces of attraction and repulsion. The zone of molecular influence extends to an appreciable distance beyond the surface of the solid particles with the result that there is a minimum distance to which the particles can approach one another. Thus other things being equal a high water content is found when the number of particles per unit volume is high. Also, the attraction for water varies from one type of clay mineral to another; especially with respect to concentration of cations. For example a sodium clay has a different affinity for water than a hydrogen clay (Kelley, 1948). For given size distribution, but different clay minerals, the water content, and hence the strength, will vary. The clay minerals also affect the water content in another way, in that water enters the lattice cells of the different clay minerals with resulting different effect on the clay. The clay mineral montmorillonite is particularly susceptible to water and hence when present in sediments is an element of weakness.

The relationship between the water content and average grain size of freshly deposited sediment is illustrated by the upper curve on Figure 1. The data for this curve were obtained by carefully sorting the particles of a given sediment into a series of size groups by means of a centrifuge so that the diameter of the largest particle in each size group was twice the smallest diameter. The different size groups, obtained in this way were shaken in water, allowed to settle, and the water content determined. As can be seen from the graph, the moisture increases in a regular manner as the grain size diminishes. 
COASTAL ENGINEERING

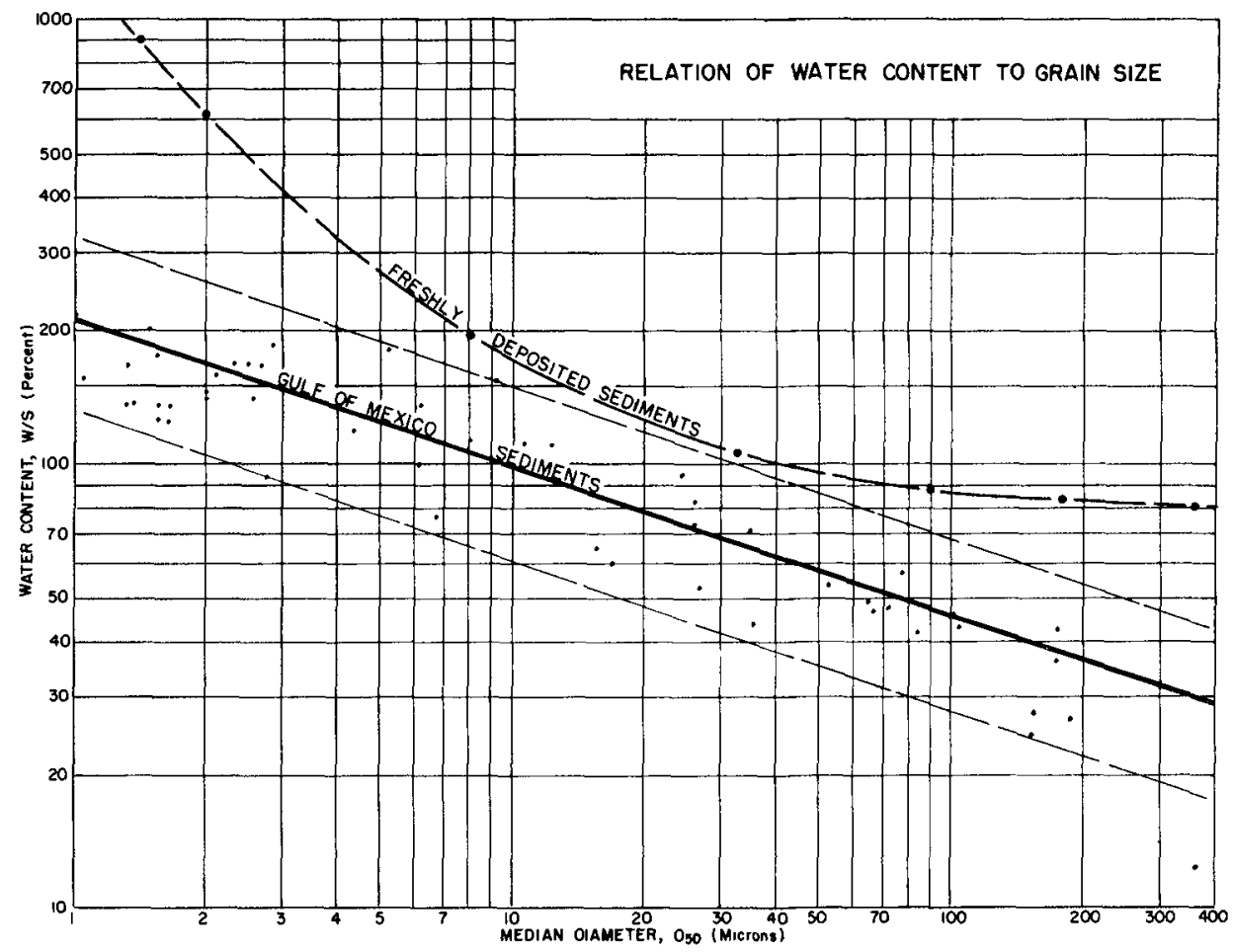

Fig. 1

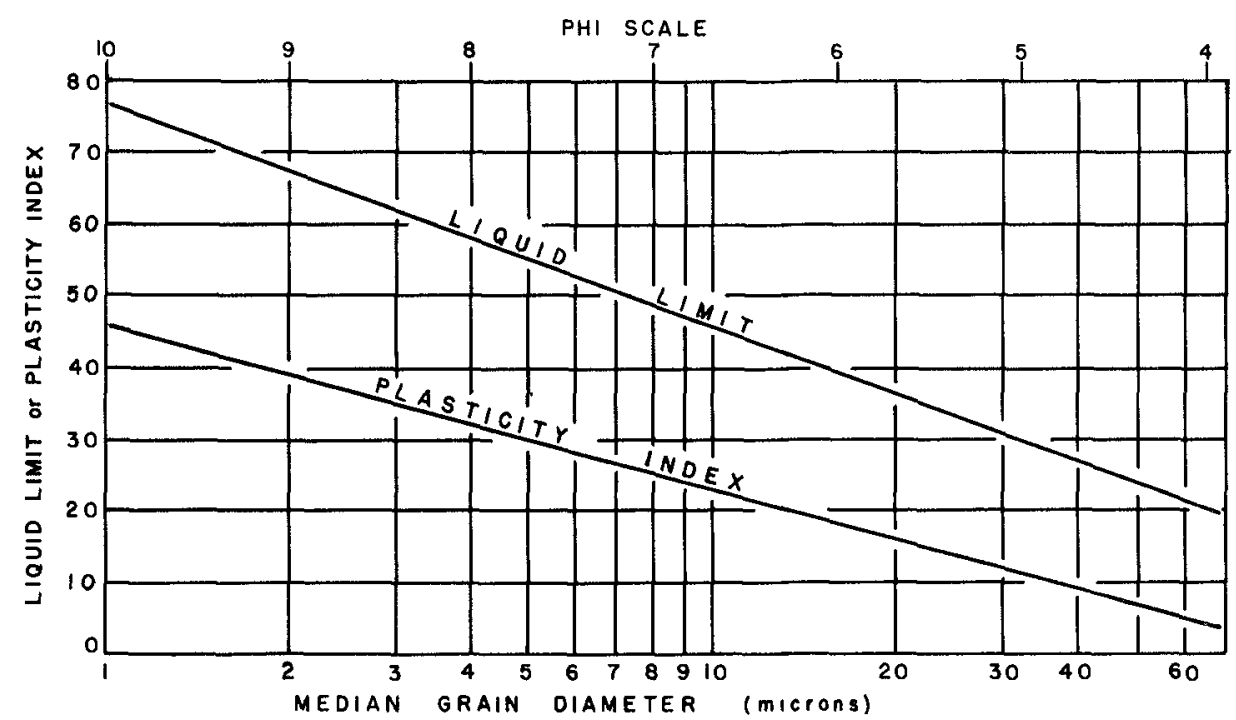

Fig. 2. Relation of Atterberg limits to grain size. 
The relationship holds for the sediment in the Gulf of Mexico, as shown by the lower curve in Figure 1. The two curves shown on this figure have different shapes, because the data for the Gulf of Mexico sedinents are based on the median diameter of the entire aggregate of particles in each sample, whereas the other curve is based on the mean of small individual size groups. The data for the lower curve are presented without regard to sorting or skewness, yet they demonstrate a definite relationship between water content and grain size, expressed by the formula: $\log _{10} W^{3}=1-\log _{10} D_{50}$ where $W$ is expressed as a ratio, and $D_{50}$ in microns. The samples on which this curve in Figure 1 are based were collected by an expedition to the Gulf of Mexico sponsored by Woods Hole Oceanographic Institute and the Geological Society of America. (Trask, Phleger, and Stetson, 1947)

The water content, as mentioned above, is influenced by the type of clay mineral. This relationship is obvious from Casagrande's (1936) classic study of the relation betwe plasticity index and liquid limit. For descriptions of these properties, see Terzaghi \& Peck (1948 p. 32). Casagrande shows that sediments in individual geologic environments have consistent relationships between these two Atterberg properties, but that the relationships may differ from one region to another. The relationship in any particular area is materially influenced by the grain size, as is illustrated by Figure 2, based on sediments in San Francisco Bay. As the Atterberg limits are measured in terms of water content, and as the water content is influenced by the grain size, they also should vary with the grain size. The Atterberg limits in Figure 2 when plotted according to the procedure of Casagrande, lie within a narrow band just above his A line, as is illustrated by Figure 3 . This band corresponds to the position of his glacial clays.

If the clay minerals are of one type, as they almost certainly must be in a small area such as San Francisco Bay, their effect on the water content should be similar from one sample to another, with the result that the relationship between Atterberg limits and grain size or between water content and grain size should be a simple linear function, but if the type of clay mineral should differ from one sediment to another, the effect of the different kinds of clay on the water content would cause appreciable deviation from the simple linear relationship between water content and grain size. It could thus be postulated that if the sediments in an individual region exhibit a consistent linear relationship between Atterberg limits and grain size, the clay minerals are similar throughout that region and if the relationship is not consistent the clay minerals are not the same throughout the region. Further research on this hypothesis might lead to useful conclusions in interpreting Atterberg tests.

The strength also depends upon the load and the length of time the load has been applied. Sediments when first deposited have the maximum possible water content. As time goes on following their burial beneath later deposits, the particles are pressed closer together, smaller grains find their way between larger grains, clay minerals grow in size, new minerals are formed, and the clay minerals flatten out. All these processes cause the water content to decrease and the strength to increase, but not necessarily to the same degree. 
COASTAL ENGINEERING

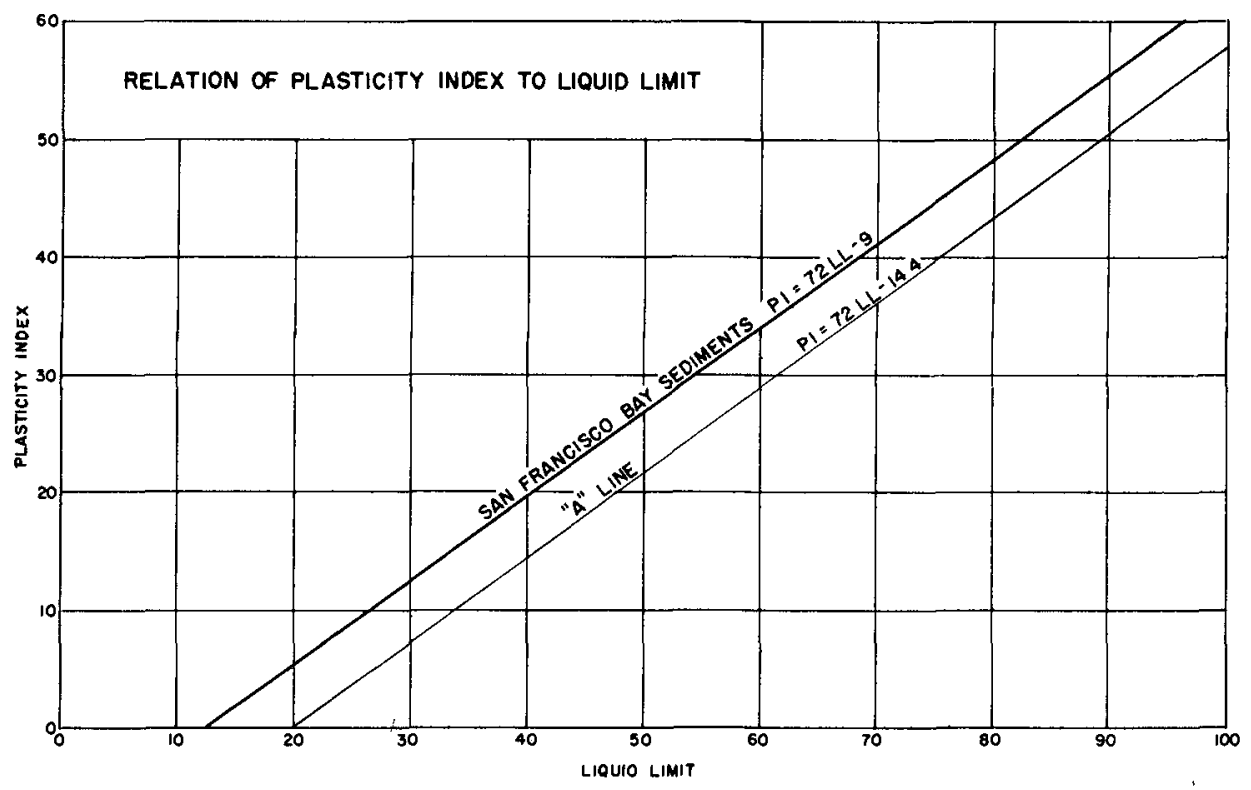

Fig. 3.

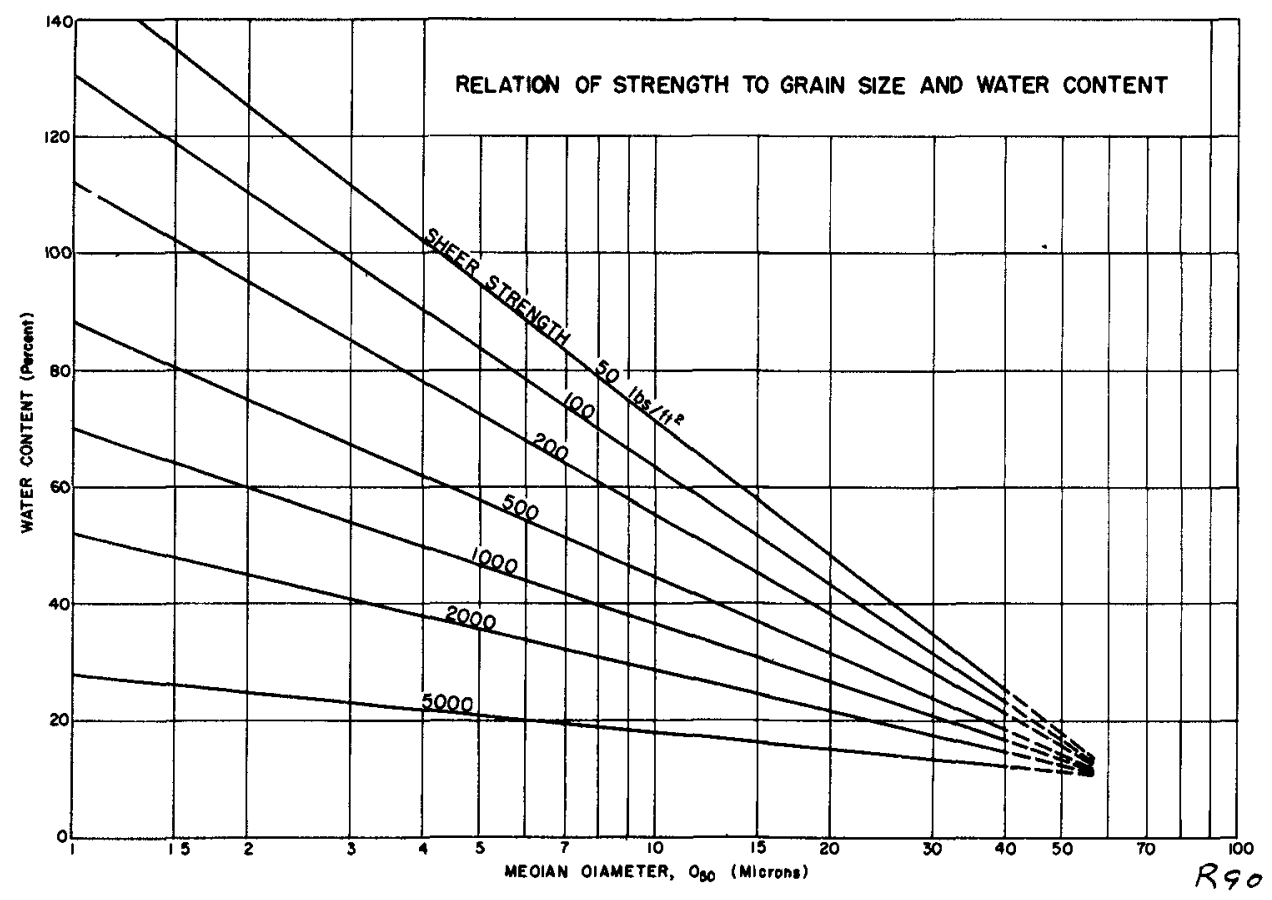

Fig. 4 . 
Soil mecharjics engineers in making consolidation tests have found that when a load is imposed upon a sediment, the water content diminishes at a uniform rate with respect to geometric increases in load once a load has been added equivalent to the normal load that overlies the sediments at the time the sample is collected. The normal rate of increase is called the compression index (Terzaghi \& Peck, 1948 p. 65). It is remarkably constant in most fine-grained sediments until the volume has been reduced to within 10 or 15 percent of the maximum possible consolidation. The last 10 or 15 percent of the consolidation, called secondary consolidation, progresses at a very slow rate and is akin to what the geologist calls geologic compaction. It does not affect the present discussion.

Freshly deposited sediments, burdened with essentially no load, could be regarded as unconsolidated. The flat part of their consolidation curves, accordingly would be small. Practically all of the consolidation curve would consist of the steep or virgin part.

This phenomenon is clearly indicated by the sediments in the Gulf of Mexico, which no matter whether fine sand, silt, or clay lose approximately 30 percent of the water in the first 12 to 20 inches of burial. This conclusion is based on a study of the moisture content of a series of cores collected on the continental shelf of Texas and Western Louisiana. (Trask, Phleger, and Stetson, 1947) Though the rate of loss with respect to depth or load in the upper layers of sediments is the same for differing grain size, the water content itself varies with grain size as shown on Figure 1 . It is low in the coarse sediments and high in the fine deposits.

The rate of $108 \mathrm{~s}$ of water also is influenced by the permeability. The greater the permeability the greater is the rate of loss. other things being equal, permeability varies with grain size and with sorting. (Krumbein \& Monk, 1942) The larger the grain size the more permeable are the sediments. Likewise, the more nearly equal the particles are in size, for given grain diameter, the more permeable is the sediment. If sediments are coarse, the pores between particles are large, and water can readily escape. If particles are all of the same size the spaces between particles are not filled with smaller particles and thus the pores are relatively large. On the other hand, poorly sorted deposits and sediments with high skewness will consolidate slowly. Ordinarily, the rate of deposition of sediments is so slow that the water content will continually be in equilibrium with the imposed load. This relationship is attested by results of consolidation tests which show that the consolidation load, Pc, is essentially equivalent to the normal load. Thus if the sediments are similar in character with depth of burial, the water content of sediments at given depth could be predicted upon the besis of the compression index. If the relation of compression index to grain size distribution is known, water content at any depth could be inferred from size distribution. A preliminary analysis of some 300 consolidation curves in San Francisco Bay shows a fairly definite relation between compression index and grain size. The finer the grain size the higher 


\section{COASTAL ENGINEERING}

the compression index. The degree of sorting and skewness of the sediments are complicating factors, and in the present stage of analysis of the results, definite generalizations cannot be given. The uniform rate of decrease in water content in the surface sediments in the Gulf of Mexico suggest that perhaps sorting and skewness are more effective factors in consolidation of these sediments than size of grain. Obviously this discussion of consolidation does not apply to sands, which cannot consolidate further after the sand grains come to rest upon one another in the position of minimum porosity.

The time factor becomes important in areas where there has been diastrophic activity, or where sea level has been lowered during some glacial epoch (Umbgrove, 1930). Under these conditions the sediments possibly may have been exposed to erosion, desiccation, or changing water content. Subsequently they may become buried beneath other deposits. The strength of the buried sediments, therefore, would depend upon the previous geologic history and would not be a simple function of depth of burial. This condition is of concern to the engineer in his concept of "preconsolidation" (Terzaghi \& Peck, 1948, pp. 67-73). Since the ovidence for a widespread lowering of sea level during the glacial epoch, with ensuing period of erosion and exposure, is constantiy increasing, it follows that sediments near rivers and harbors along the coast have been subject to erosion or desiccation. Glacial lowering of sea level would be worldwide. Thus engineers should consider the possibility of encountering preconsolidated sediments at shallow depth, when dealing with problems of coastal engineering. On the Gulf Coast, as Russell (1952) in his paper for this Second Conference on Cosstal Engineering has shown, the pleistooene Lissie formation has been found beneath younger deposits. Accordingly, it may be encountered within shallow depth near shore.

For given grain size, strength of sediment varies with the water content. This phenomenon is characteristic of consolidation, because, as individual sediments consolidate under increased loads the water decreases. The load thus is carried to a progressively greater extent by the solid constituents. That is, more of the solid particles press against one another and the greater is the resulting strength. In San Francisco Bay the strength of the sediment has been found to vary with the grain size and water content (Trask \& Rolston, 1950). The relationship is indicated by the equation:

$$
S_{s}=\log _{10}^{-1}\left(\frac{7.5-3 \mathrm{~W}-4 \log _{10} D_{50}}{1.8-\log _{10} D_{50}}\right)
$$

where $S_{s}$ is the shear strength expressed in pounds per square foot (onehalf the unconfined compression $Q u / 2$ ), W is the moisture content expressed as the ratio of weight of water to weight of solid particles; and $D_{50}$ is the median diameter in microns. (This equation is presented graphically in Figure 4.)

The relationship found in San Francisco Bay cannot be accepted as any general principle until other areas have been studied in like manner. 


\section{STRENGTH OF SEDIMENTS IN THE GULF OF MEXICO}

Since the water content depends to some extent on the type of clay minerals, and since the strencth is influenced by the sorting and skewness of the constituent particles, the numerical relationship expressed graphically in Figure 4 may differ in different regions. However it is possible that a similar relationship exists in almost any area where the clay minerals are not too variable in composition.

As applied to the Gulf of Mexico, the strength of sediments at a depth of one foot beneath the surface would average 150 lbs. per square foot and range almost entirely between 50 and 250 pounds per square foot. Data from consolidation tests would materially help the prediction of strength at greater depths.

\section{MINOR FACTORS}

The minor factors that influonce strength need be discussed but briefly. As a rule they affect the strength relatively little. The shape of the particles is possibly the most important minor factor, though conceivably desiccation locally may be more significant. If sand grains are well rounded they do not wedge into one another effectively; hence the sand is less stable than if the sand is composed of angular constituents. Similarly the platelike clay minerals conceivably could form planes of weakness upon which the sediment might slip under tangential stress. Also, the different clay minerals may have different affinities for water and hence different strength relationships. (Kelley, 1948).

In general the effect of mineral constituents, other than clay minerals may be assumed to be minor, as one mineral differs very little from another mineral as a means of imparting physical strength. Except for clay minerals, the great bulk of the constituent particles of sediment are composed of quartz and feldspar, which are similar in character. Minor minerals such as mica, zircon, or hornblende might have characteristic shapes which compared with other minerals might impart additional strength or weakness to sediment, but only to a minor degree. lifica possibly might be most effective in this respect. It consists of flat plates that provide horizontal planes of weakness.

In the course of geologic time old minerals grow in size and new minerals form, thus imparting strength. Some of the newly formed minerals are deposited in such abundance as to form cement. This cement influences considerably the rate at which water circulates through the sediments. Base exchange affects the properties of clay minerals. In the course of time, it even may result in the formation of clay minerals of a different type and different affinity for water than originally present in the sediments, with resulting change in strength. Biological activity is restricted mainly to the upper layers of sediments, though bacteria can be expected at any depth. The by-products of these living organisms conceivably could affect base exchange, hydrogen ion concentration, and reducing potontial, but as the ef fect of living organisms is 


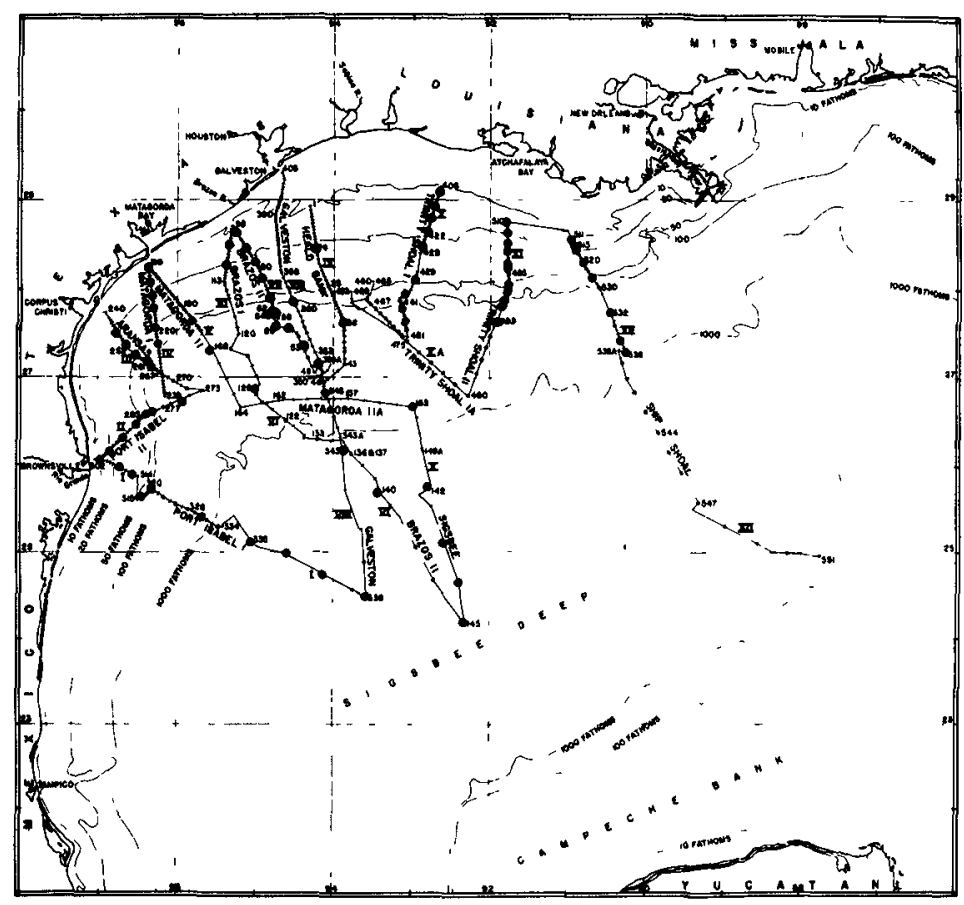

GULF OF MEXICO, WESTERN PART

STATIONS OCCUPIED DURING ATLANTIS CRUISE, 1947

- WATER CONTENT SAMPLES
SPONBOREO SY WODOS MOLE OCEAMOENAPAC IMSTITUTIOO

AHO GEOLOAIEAL SOEIETY of AMERIEA

Fig. 5.

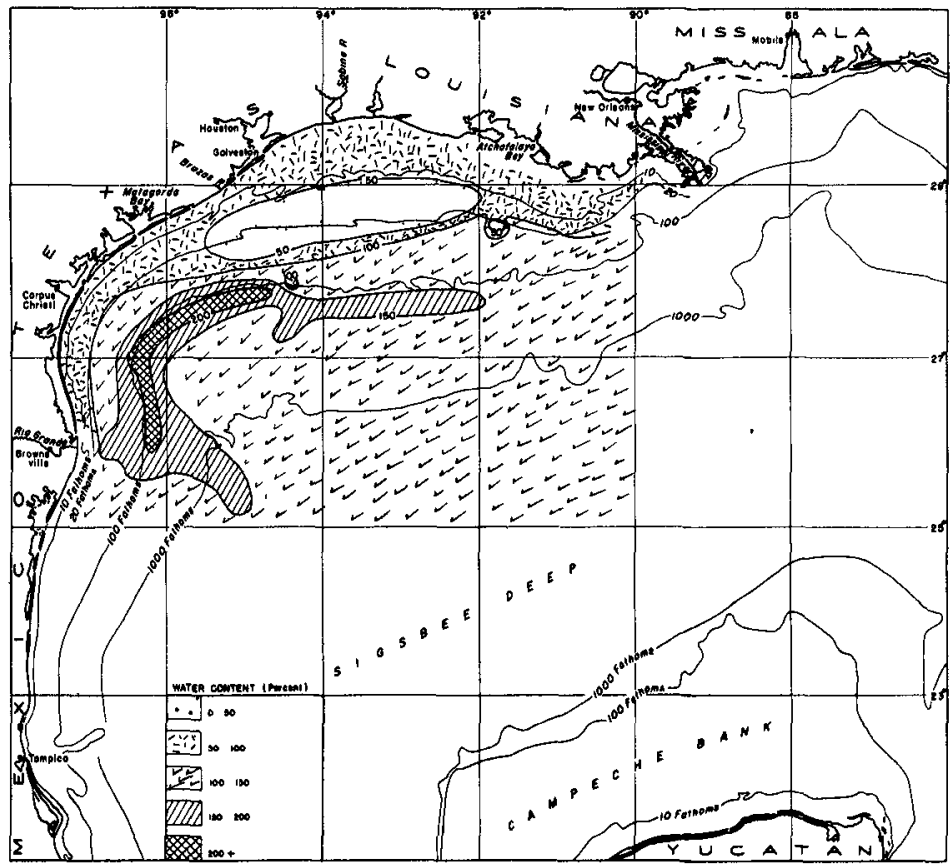

Fig. 6. Water content of sediments, Gulf of Mexico. 


\section{STRENGTH OF SEDIMENTS IN THE GULF OF MEXICO}

largely restricted to the upper layers of sediment, the effect of organisms on strength ordinarily is small. Continued ingestion of sediments by worms and other bottom living organisms perhaps may affect the ultimate strength characteristics of the sediments, particularly fine-grained sediments. The hydrogen-ion concentration, reducing potential, temperature, variations in temperature, chemical content of contained water influence strength properties, such as comentation, base exchange, and growth of clay minerals; but the overall effect on strength as a rule presimably is small. Earthquake vibrations might cause sands to settle and can break up bonds between clay minerals that have started to grow together, thus weakening the sediments. The effects of diastrophic deformation and erosional history have already been discussed. Tides, by exposing sediments alternately to water and to air and also by changing the pressure to a more or less slight extent upon the underlying sediment, might exert a minor influence on the strength of sediments. Berometric pressure could act similar to tides. Also, microseisms caused by intensive barometric disturbances perhaps might lessen bonds between mineral constituents.

\section{SPECIFIC CONDITIONS IN THE GULF OF MEXICO}

This paper is written without benefit of engineering data on the sediments of the Gulf of Mexico. Obviously, the geologic conditions must be tied in with engineering data before they can be used effectively in predicting strength of sediments in any new area such as the Gulf of Mexico. The sediments in this area in general are soft. The water content as indicated by a series of samples collected by the Atlantis expedition to the Gulf of Mexico in 1947 (Trask, Phleger \& Stetson, 1947), are soft. The location of the samples collected is given in Figure 5, and the areal distribution of water content in Figure 6.

The sediments lying between depths of 10 and 20 fathoms in an area bordered on the west by the Brazos River and on the east by the Atchalafaya River are much coarser and have a lower water content than deposits in adjacent waters. The strength of the sediments in this central area, therefore, should be greater than in other areas. About 15 of the samples taken, indicated by small dots in Figure 5, were cores ranging up to 10 feet in length. The water content of long cores was not determined, because there was no practicable means of measuring the water content accurately without interfering seriously with other studies that were planned for these cores. The water content was determined on short cores specially collected for such analyses. These cores range in length up to 20 inches. They were hermetically sealed as soon as collected and analyzed shortly thereafter, in order to minimize possible loss of water through tho seals at the ends of the tubes.

As mentioned above, the moisture content of the sediments at the bottom of the tube was approximately 30 percent less than in the upper part. The loss was essentially the same for sand, silt, or clay. The texture of the sediment at the bottom of most of the cores collected for water analyses was approximately the same as at the surface. In a few samples where the bottom of the core was coarser than the top, the 


\section{COASTAL ENGINEERING}

water content was correspondingly lower, but in others, the upper part was coarser than the bottom part, and the moisture content was correspondingly higher. With respect to the overall average loss of 30 percent water, the effect of these two differences largely counterbalanced each other.

\section{CONCLUSION}

The argument as developed in this paper has been largely theoretical, because of the scarcity of data correlating the geologic characteristics of the sediment with the strength for engineering purposes. With what is now known about the relation of strength to grain size, and if the general distribution of grain size and water content, in the upper 100 to 150 feet of sediment in the Gulf of Mexico were known, it should be possible to estimate the strength of sediments for preliminary design planning. It is almost certain that the rate of change of geologic characteristics of sediments from place to place in the shallow water areas of the Gulf is slow and that once criteria for correlating geologic characteristics of sediment with strength are available, it should be possible for the geologist effectively to help the engineer in planning offshore drilling operations.

\section{REFERENCES}

Casagrande, A. (1936). The determination of the preconsolidation load and its practical significance: First Intermational Conference on Soil Mechanics and Foundation Engineering, vol. III.

First and Second International Conferences on Soil Mechanics and Founda-

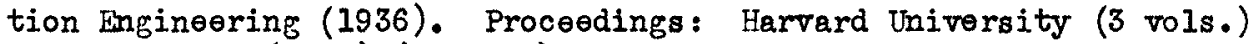
and Rotterdam (1948) (5 vols.) Symposiums on fundamentals of soil mechanics.

Kelley, W. P. (1948). Cation exchange in soils: Amer. Chem. Soc. Monograph 109.

Krumbein, W. C. and Monk, G. D. (1942), Permeability as a function of the size parameters of unconsolidated sand: Amer. Inst. Min. Engr., Trans., vol. 152, pp. 153-163.

Krumbein, W. C. and Pettijohn, F. J. (1938). Manual of sedimentary potrography: Appleton Century Co., pp. 228-267.

Russell, R. J. (1952). Recent geology of coastal Louisiana: Second Conference on Coastal Engineering, Council on Wave Research, Berkeley, California.

Terzaghi, K., and Peck, R. B. (1948). Soil mechanics in engineering practice: John Wiley and Sons, pp. 1-136.

Trask, Parker D., and Rolston, J. W. (1950). Relation of shear strength of sediments to water content and grain size: Science, vol. 11l, pp. 666, 667. 
Trask, Parker D., and Rolston, J. W. (1951). Engineөring geology of San Francisco Bay: Geol. Soc. Amer. Bull., vol. 62, pp. 1079-1109.

Trask, Parker D., Phleger, F.B., and Stetson, H. C., (1947). Recent changes in sedimentation in the Gulf of Mexico: Science, vol. 106 , pp. 460-461.

Jmbgrove, J.H.F. (1930). The anount of maximum lowering of sea level in the Pleistocene: 4th Pacific Science Congress, Proc., vol. 2, pp. 105-110. 